\title{
La produccion de café especial y cacao, ventajas competitivas para el desarrollo sostenible de la empresa asociativa rural
}

\section{The production of special coffee and cocoa, competitive advantages for the sustainable development of rural associative enterprise}

DOI: 10.54018/sssrv3n1-009

Recebimento dos originais: 15/01/2022

Aceitação para publicação: 15/02/2022

\section{Carlos Vidal Tovar}

Doctor en Ciencias, Mención Gerencia. Docente Universidad Popular del Cesar Universidad de Santander - UDES. Valledupar - Cesar, Colombia

E-mail: car.vidal@mail.udes.edu.co - carlosvidal@unicesar.edu.co

\section{Yimy Gordon Hernández}

Doctor en Ciencias Gerenciales

Docente Universidad Popular del Cesar

Valledupar - Cesar, Colombia

E-mail: yimygordon@unicesar.edu.co

\section{Adalberto Vides Redondo}

Magíster en Gerencia de Proyectos de Investigación y Desarrollo Docente Universidad Popular del Cesar. Valledupar - Cesar, Colombia E-mail: adalbertovides@unicesar.edu.co

\section{Yimmis A. Pérez Rojas}

Magister en Dirección Estratégica de Calidad, Medio Ambiente y Riesgos Laborales

Docente Universidad Popular del Cesar. Valledupar - Cesar, Colombia

E-mail: yimmisperez@unicesar.edu.co

\section{Milagro del Carmen Patrón Noriega}

Doctora en Ciencias de la Educación. Docente Universidad del Magdalena Santa Marta, Magdalena, Colombia

E-mail: mpatronn@unimagdalena.edu.co

\section{RESUMEN}

El propósito de este trabajo es dar a conocer como las empresas asociativas rurales de cafés especiales y cacao en el Departamento del Cesar contribuyen desde sus acciones a los Objetivos de Desarrollo Sostenibles - ODS, Para lo cual fue necesario la identificación de los factores que llevaron a su creación; la caracterización de su estructura organizacional y la descripción de sus ventajas competitivas desde sus procesos de producción. Los datos fueron tomados desde la interacción social y participativa por medio de una entrevista estructurada a 
miembros de la junta directiva de 10 empresas asociativas que voluntariamente accedieron a participar en la investigación.

Palabras claves: Producción primaria, transformación, Postcosecha, Sistema Agroforestal.

\section{ABSTRACT}

The purpose of this work is to publicize how rural association companies of specialty coffees and cocoa in the Department of Cesar contribute from their actions to Sustainable development goals - SDG, for which it was necessary to identify the factors that led to its creation; characterizing its organizational structure and describing its competitive advantages from its production processes. The data were taken from social and participatory interaction through a structured interview with board members of 10 association companies who voluntarily agreed to participate in the research.

Keywords: Primary production, transformation, postharvest, Agroforestry system.

\section{INTRODUCCIÓN}

Acorde con el banco Mundial (2001), las organizaciones de productores son organizaciones rurales formales constituidas por miembros organizados con el fin de aumentar sus ingresos por medio del mejoramiento de sus de actividades de producción, comercialización y elaboración de productos a nivel local. Es decir, tienen en su propósito social la función de organizar las relaciones con el exterior. Son estructuras de interrelación que, según el caso, pueden ser un medio para facilitar o acelerar la integración de la población rural en el mercado y en la sociedad global.

En ese sentido, la asociatividad campesina es el producto de una serie de acciones o estrategias de mejoramiento progresivo. En ellas están vinculadas grupos de personas con diferentes formas de pensar, los cuales deben ser eficientes en el desarrollo empresarial, sin perder su propósito en lo social y comunitaria. El carácter asociativo se convierte en el motor motivacional para la participación colaborativa, la toma de decisiones, el control a sus líderes, el funcionamiento de sus comités y sus entes organizativos (Chiriboga y Arellano, 2007). La asociatividad se relaciona con la cooperación, el capital social y la confianza. En términos más específicos se relaciona con el emprendimiento empresarial y los incentivos existentes para iniciar y desarrollar acciones económicas colaborativas. 
En consonancia con la FAO (2015), es difícil cuantificar la importancia de la Pequeña Producción Agraria en la región por la ausencia de información sistematizada, pero si es posible una aproximación tomando como base el tamaño de la finca. La pequeña producción agropecuaria es importante en todas las subregiones de América Latina y en casi todos los países. En Centroamérica y en los países andinos es donde tiene un peso relativamente menor, dado la predominancia del minifundio. Resulta más difícil realizar una cuantificación que tenga en cuenta el carácter de subsistencia o capitalizado. Los pequeños productores agropecuarios desempeñan un papel extremadamente significativo en la producción agropecuaria de la mayor parte de los países. Esto se debe tanto a la importancia que este tipo de productores da a la subsistencia, como al efecto de las políticas públicas que buscaron convertirlos en los abastecedores fundamentales de alimentos para las grandes ciudades (FAO, 2015).

En Colombia, el Ministerio de Agricultura Y Desarrollo Rural - MADR, por medio del Decreto 938 de 1995, regula el marco jurídico de las asociaciones agropecuarias y campesinas, para lo cual "se entiende por asociación agropecuaria la persona jurídica de derecho privado y sin ánimo de lucro, constituida por quienes adelantan una actividad agrícola, pecuaria, forestal, piscícola y acuícola o por quienes representen actividades agroindustriales o de servicios complementarios de la producción agropecuaria, con el objeto de defender o representar los intereses comunes de sus asociados y contribuir al desarrollo del sector rural nacional".

\section{METODOLOGIA}

El procedimiento ordenado para dar a conocer como las empresas asociativas rurales de cafés especiales y cacao en el Departamento del Cesar contribuyen desde sus acciones a los objetivos de desarrollo sostenibles, fue realizado durante el año 2018 a partir de un análisis de datos cuantitativos y cualitativos bajo el enfoque mixto, de tipo descriptivo, de campo, transeccional y no experimental tomando como base los preceptos propuesto por Hernández y Otros (2010); Hurtado de Barrera (2010); Bavaresco (2009) y Vieytes (2004).

La información se tomó desde la interacción social y participativa con miembros de la junta directiva de 10 empresas asociativas, cinco productoras de 
cacao y 5 productoras de Café Especial que voluntariamente accedieron a participar en la investigación, para esto se utilizó como técnica de recolección de datos una entrevista estructurada aplicada en tres reuniones realizadas con la junta directiva de cada asociación liderada por su representante legal; la entrevista de 10 preguntas se orientó a recabar la información de cada empresa asociativa teniendo en cuenta los principales aspectos que llevaron a su creación; la conformación de su estructura organizacional para la toma de decisiones y la descripción de los componentes de la cadena de valor y las alianzas de cada empresa asociativa.

También se realizaron 5 reuniones con entes públicos privados involucrados en la dinámica de estas asociaciones tales como Alcaldías, Corporación Regional Autónoma y Juntas Comunales. Igualmente se realizó una revisión de documentos suministrados por cada empresa con el fin de validar y comprobar los datos obtenidos en la entrevista. La información se sistematizó en una matriz de análisis documental desarrollada en la hoja de cálculo Excel, del paquete de Microsoft Office versión 2013, de allí se analizó el contenido para interpretar y teorizar la información de cada empresa asociativa vinculada con los objetivos propuestos en este trabajo.

\section{RESULTADOS}

A continuación, se presentan el análisis de los principales resultados.

\subsection{FACTORES VINCULADOS A LA CREACIÓN DE EMPRESAS ASOCIATIVAS DE CAFÉ ESPECIAL Y CACAO EN EL DEPARTAMENTO DEL CESAR}

El primer factor destacado por las asociaciones vinculadas al estudio se refiere a la oportunidad presente en la región para desarrollar estos cultivos. La zona de producción de café y cacao en el Departamento del Cesar está localizada en los municipios que forman parte de la Sierra Nevada de Santa Marta y Serranía del Perijá, sus habitantes están constituidos por colonos, comerciantes, campesinos y comunidades indígenas, quienes en torno a la vocación agrícola pecuaria especialmente conformados en asociaciones formalmente constituidas dedican gran parte de sus actividades productivas generadas por la explotación de estos cultivos. Municipios como Pueblo Bello, Valledupar, Manaure, San Diego, 
La Paz y Codazzi, entre otros, albergan un sin número de productores de Café y Cacao que aprovechan las condiciones climáticas y edafológicas para cultivar estos productos.

Otro aspecto importante se refiere al contexto socioeconómico vivido en la zona, entre 1985 y 2015 el fenómeno de violencia originado por participación armada de Guerrillas y Paramilitares se manifestó en esta región de una forma exacerbada que no tuvo distingo alguno con sus habitantes. Las tierras del Cesar, han sido objeto de una intensa disputa. En comparación con otros departamentos de Colombia, la economía del Cesar es de tradición agrícola pecuaria y se ha deteriorado en los últimos treinta años por el accionar de estos grupos ilegales que dejaron a su paso un sin número de víctimas en todos los estratos sociales, entre ellos, miles de pequeños productores agrícolas o campesinos que abandonaron, mal vendieron o fueron obligados a salir de sus fincas lo que trajo como consecuencia la baja productividad de miles de hectáreas, el abandono del campo y la degradación de la familia en todos los aspectos.

Lo anterior despertó el interés y la necesidad de sacar adelante a la unidad productiva agrícola, utilizar su "finca" como medio de sostenibilidad económica para su núcleo familiar. La estrategia colaborativa y asociada se presenta como una opción para el pequeño productor agrícola con el fin de buscar una forma de mitigar el impacto mencionado anteriormente. Hoy día, más del $80 \%$ de los miembros vinculados a asociaciones de Café y Cacao se encuentran visibles en el Registro Único de Víctimas del Gobierno de Colombia.

Otro factor manifestado por los líderes asociativos es el acompañamiento desarrollado por la Federación Nacional de Cafeteros - FNC y la Federación Nacional de Cacaoteros - FEDECACAO; estas dos entidades son los gremios legalmente constituidos para representar y defender los intereses de productores colombianos con el fin de implementar estrategias en investigación, Extensión rural y comercialización para contribuir al fortalecimiento de los eslabones que conforman las cadenas productivas. 


\subsection{CARACTERÍSTICAS DE LA ORGANIZACIÓN DE ALGUNAS ASOCIACIONES DE CAFÉ Y CACAO EN EL DEPARTAMENTO DEL CESAR.}

Acorde al análisis de la información de campo, se determinó que las asociaciones vinculadas con el estudio se encuentran formalmente establecidas y registradas en Cámara de Comercio a partir del año 2000, el $80 \%$ poseen oficinas y demás infraestructuras en el área urbana de las cabeceras municipales; mientras que el $20 \%$ restante las tiene en las áreas rurales. De ellas, el $60 \%$ de las empresas asociativas poseen menos de 100 asociados, el 30\% tienen entre 100 y 200 asociados y solo el $10 \%$ posee más de 500 socios.

En ese orden, todas estas empresas poseen una estructura organizacional vertical, donde la máxima autoridad es la Asamblea General, a la cual se presentan los socios activos y a paz y salvo para ejercer su voto hacia la toma de decisiones. En segundo orden de jerarquía se encuentra la Junta Directiva, sus miembros son elegidos en asamblea general para un periodo comprendido entre 2 a 4 años, se encuentra conformada 5 a 7 miembros, quienes se reúnen entre 1, 3 o 6 meses o extraordinariamente cuando se presente alguna necesidad que exija decisiones de tipo asamblea general.

Aunado a lo anterior, las juntas directivas de las empresas asociativas participantes están conformadas por un presidente que hace las veces de representante legal y gerente; un Vicepresidente; un Secretario, vocales, suplentes y revisor fiscal. Cuentan con estatutos, libros de Actas de Asamblea, libro de actas de reuniones de Junta Directiva y estados financieros entre otros. Se pudo observar que las funciones de los miembros de la Junta Directiva están claras y bien definidas en los estatutos, pero algunas veces son muy poco identificadas y conocidas por las personas que ejercen un cargo determinado y en quienes recae la responsabilidad. Se comprobó que en algunas asociaciones se cobra una cuota de afiliación que oscila entre $\$ 20.000$ a $\$ 200.000$, al igual que una cuota de sostenimiento anual por el mismo valor, esta cuota algunas veces el asociado la paga de forma fraccionada o con la producción de su unidad productiva.

En todas las asociaciones se determinó que existen morosos con aportes de estas cuotas u otros dineros de actividades realizadas, lo cual es causal de retiro de la asociación en algunas. Igualmente, solo el $10 \%$ de las empresas 
asociativas participantes posee un fondo rotatorio como estrategia de ahorro y capitalización estructurada a partir de un pequeño porcentaje de las utilidades de su producción para prestar recurso económico y ayudar con sus necesidades a los mismos asociados.

Por otra parte, en el orden jerárquico establecido en los estatutos de las empresas asociativas participantes se encuentran el funcionamiento de comités técnico, social y de veeduría con el fin de apoyar los procesos administrativos de la junta directiva. Estos comités funcionan en el $40 \%$ de estas asociaciones, mientras en el $60 \%$ restante están creados en el "papel" mas no operan acorde a sus estatutos. Igualmente en un $30 \%$ de las asociaciones se observó en campo que el representante legal es quien asume las diferentes gestiones organizativas, de contacto y convocatoria a los asociados, de hecho el $20 \%$ de las asociaciones tiene problemas de comunicación por su localización en área rural sin señal de telefonía celular, sin embargo, todas las asociaciones cuentan con una importante presencia territorial en la zona y mantienen las buenas relaciones con otras asociaciones presentes en la zona; además, algunas comparten los mismos espacios con la junta comunal o comunidades indígenas.

Además, el $60 \%$ de las empresas asociativas prestan a sus asociados asistencia técnica directa, adicional a la realizada por las entidades gremiales. EI $40 \%$ restante depende de otras entidades gremiales, entidades territoriales o de proyectos que llegan a la zona algunas veces como apoyo a la asociación o de participación independiente por el asociado. También, el dialogo con los miembros de las juntas directivas permitió establecer que la mayoría de los asociados no llevan cuentas o registros de su producción y ventas; presentan dificultades para identificar unidades de medida, algunos llevan registro de mano de obra, mas no de gastos de insumo o registros de los gastos que se han generado en el ejercicio productivo. Algunos no tienen claridad sobre las áreas cultivadas o número de plantas establecidas, confunden los gastos del hogar con los gastos de insumos y materias primas de la unidad productiva.

Desde lo anterior, se puede comprobar como la creación de Empresas Asociativas se alinean con lo propuesto en los ODS; sus 17 objetivos hacia la búsqueda del desarrollo económico, ambiental y social de forma participativa e inclusiva. En este caso al favorecer la organización de pequeños productores de 
escasos recursos económicos, desplazados por el fenómeno de violencia aprovechan su conocimiento, vocación campesina y competencias específicas entorno al Café especial y al Cacao para generar empleo digno, trabajar en unión de la familia y su comunidad, con estilo de gobernanza propia, ajustada al marco legal colombiano para formalizar su empresa productiva, ser parte del entramado empresarial y aprovechar de forma sostenible las condiciones y oportunidades del recurso tierra en sus pequeñas unidades productivas.

\subsection{VENTAJAS COMPETITIVAS DE LAS EMPRESAS ASOCIATIVAS DE CAFÉS ESPECIALES EN EL DEPARTAMENTO DEL CESAR}

Al norte de Colombia se localiza el Departamento del Cesar, en su producción agrícola se destaca uno de los mejores cafés suaves del país, reconocido con la denominación de origen "Sierra Nevada", se produce en las laderas de la Sierra Nevada de Santa Marta y Serranía del Perijá por pequeños caficultores localizadas por encima de los 1200 msnm en 19 municipios cafeteros del Departamento del Cesar. Este cultivo, es el medio de subsistencia de 8.595 familias cafeteras que a través de sistemas agroforestales lo obtienen en un área aproximada de 29.034 hectáreas (Comité de cafeteros del Cesar y la Guajira, 2016).

Acorde a la información recabada, la cadena productiva de cafés especiales beneficia a 2.605 familias cafeteras localizadas en comunidades campesinas e indígenas que cultivan 10.462 hectáreas en sus pequeñas unidades de producción por medio de sistema agroforestal, de estas, el 57\% están certificadas en producción orgánica, igualmente el 94\% posee certificación en comercio justo. La producción anual estimada de café especial en kilogramos de café pergamino seco CPS es de 7.436 .695 kilos que equivalen al 46,5\% de la producción estimada para el departamento del Cesar y la producción de café especial aporta un valor de cosecha de 48.658 mil millones de pesos (USAID CORPORACIÓN PBA y PTDR, 2017).

En ese sentido, La cadena de valor de cafés especiales inicia con los pequeños productores que forman parte de las empresas asociativas, sus unidades productivas Poseen en promedio de 2 a 3,5 hectáreas sembradas en Sistema Agroforestal, con densidades de siembra entre 3500 a 6000 plantas de 
café por hectárea; en suelos con topografía ondulada a quebrada, El agua se toma de fuentes de agua naturales provenientes de nacederos en las faldas de las fincas, o de corrientes que las atraviesan. En estas comunidades siembran el café de forma tradicional acorde al régimen de lluvia; la gran mayoría estableces sus cultivos sin un análisis de suelos y es baja su disponibilidad de dinero para establecer un plan de abonamiento que garantice un adecuado suministro de nutrientes desde un comienzo que permita alcanzar la productividad y las producciones esperadas (1.100 Kg/ha a partir del cuarto año).

El cultivo de café especial en la región pertenece a la especie arábiga, se cosecha cuando el grano está maduro entre la semana 32 y 33 después de la floración, aproximadamente entre los meses de septiembre a noviembre. Los productores cafeteros manifiestan de forma abierta su vocación generacional, su amor, optimismo y compromiso por producir el mejor café del mundo, así mismo expresan tener aspectos diferenciales en su cultivo que a todos cuentan y que hace a su café único, es algo cultural ligado a las buenas practicas del caficultor en su unidad productiva, lo cual hace que el nuevo cliente se sienta atraído por la historia de ese café, quiera más información o conexión con su taza de café y satisfacer algo más que una necesidad corporal.

Seguido a la cosecha viene el beneficio del café, es muy importante en la calidad del café especial en sus características físicas y sensoriales, requiere de mano de obra con conocimiento en su proceso para evitar problemas en cada una de sus operaciones como son el despulpado, fermentación y lavado.

El despulpado se realiza inmediatamente se coseche el grano y de su proceso depende la calidad de la taza, terminada la recolección los granos se transportan al beneficio para iniciar el despulpado previo al ingreso a la maquia despulpadora se realiza el flote de cereza para retirar las cerezas brocadas o con granos balsos que pasan a un proceso independiente. Esta selección continúa manteniendo la calidad del grano. El despulpado es la separación de la cascara y pulpa del grano. Este proceso se realiza con una maquina calibrada que no parta el grano. Igualmente se tiene en cuenta que los frutos sin despulpar y la pulpa en el grano incrementan el fermento que afecta la calidad. Dentro de las buenas prácticas agrícolas el mantenimiento y limpieza de la máquina despulpadora es clave para evitar daños en el grano y pérdida de calidad. 
La Fermentación inicia una vez terminada la labor de despulpado, los cafés especiales buscan en esta labor potenciar los sabores y aromas del grano, Durante este proceso el mucilago se degrada a partir de la acción de levaduras y bacterias que por medio de enzimas descomponen los azucares del mucilago. Los productores reconocen la importancia de este proceso como factor determinante en la calidad física y sensorial del café, saben que se puede afectar por temperaturas y volúmenes utilizados. Igualmente son conscientes que la fermentación ideal potencia las notas afrutadas, dulces y de chocolate del café. Una inadecuada fermentación tendrá por resultado sabor vinagre, metálico y seco. Una vez degradado el mucilago esto permite el lavado del grano para retirar el mucilago de manera fácil y pasar a la etapa de secado. La fermentación es realizada entre 12 y 16 horas, si se excede este tiempo el grano se mancha, pierde peso se avinagra y la almendra pierde calidad. Para conservar la calidad se debe utilizar agua limpia y no mezclar en el tanque fermentador lotes de café despulpados de diferentes días.

Posterior a la fermentación, el grano es lavado para eliminar totalmente el mucilago con agua limpia para evitar defectos como el manchado, sucio, fermento y contaminado. Así mismo se clasifica por flotación en el tanque de fermentación. Después del proceso de beneficio húmedo, le continúa el proceso de secado que requiere de mano de obra para esta actividad, este proceso consiste en disminuir la humedad del grano hasta un $12 \%$, para permitir un almacenamiento seguro sin adquirir malos olores y hongos. Acorde a lo observado, el pequeño productor cafetero realiza un presecado en patios adaptados de secado o en marquesinas de $2 \mathrm{~m} \times 10 \mathrm{~m}$ en promedio. Esta última opción es la que se implementa generalmente en las fincas cafeteras del Cesar, pero no alcanzan a cubrir los requerimientos de la cosecha y por ello muchos productores baja su café a los centros poblados para terminar este proceso en patios de secado o silos.

De las asociaciones participantes en este trabajo, el $80 \%$ poseen silos de secado con capacidad de proceso de 2500 a 6000 kilos por lote de producción, estos silos funcionan en el casco urbano del municipio de Pueblo Bello y trabajan lotes de proceso por un tiempo de 30 horas. Igualmente, todas las empresas asociativas compran a sus asociados secan y tienen centros de acopio para almacenar adecuadamente el café pergamino seco para proceder con la 
comercialización, solo el $20 \%$ comercializa de forma independiente a compradores extranjeros, posee su laboratorio de calidad, compra y vende por calidad de tasa. El resto comercializa con Caficosta, compra y vende acorde al aroma, el color, el tamaño, la humedad y la textura del café pergamino seco.

Inmediatamente, se eliminan todas las impurezas, granos mohosos, partidos y vanos, mediante un proceso manual o con zarandas, dejando únicamente los granos sanos y secos. Los granos seleccionados se empacan en sacos de fique de 50 kilos, nuevos o de segunda en perfecto estado, lavándolos para evitar que estén contaminados. Por último, se hace una prueba de calidad que consiste en tomar un grano y hacer un corte longitudinal al grano, separando los dos cotiledones para observar las características del grano, con el fin de ajustar prácticas de beneficio y mejorar la calidad.

Como se pudo observar, la fortaleza de las asociaciones se centra en la comercialización de café pergamino acorde a los atributos del aroma, el color, el tamaño, la humedad y la textura del café obtenido. También, ninguna de las asociaciones comercializa café tostado y molido, solo una recientemente adquirió por medio de un proyecto de alianza productiva una planta de tostión con trilla y molido de café pergamino seco con el fin de aprovechar sus excedentes e incursionar en este mercado

\subsection{VENTAJAS COMPETITIVAS DE LAS EMPRESAS ASOCIATIVAS DE CACAO EN EL DEPARTAMENTO DEL CESAR}

Al igual que el Café, por medio de la información recabada en las empresas asociativas participantes, la cadena de valor del Cacao inicia con los pequeños productores cacaoteros vinculados a las empresas asociativas constituidas en promedio por 72 miembros que poseen un área promedio de 2 a 2,5 hectáreas sembradas y su producción no supera los 350 kilogramos al año. Las actividades que aportan ventaja competitiva o las operaciones desde el cultivo hasta su comercialización se describen a continuación.

Las unidades productivas en su mayoría, poseen plantas de cacao sembradas entre los años de 1999 a 2003 por proyectos del Plan Colombia por medio de "Misión Animar", actualmente las áreas cultivadas se encuentran en un sistema agroforestal compuesto por arboles maderables y frutales propios de la 
región creando un ambiente adecuado desde la sombra, microclimas y temperaturas adecuadas para que el árbol de cacao exprese sus mejores características fisiológicas. Las fincas o pequeñas unidades productivas están localizadas entre los 500 a 1200 metros sobre el nivel del mar.

Son muy pocas las unidades productivas que cumplen con los 1100 árboles por hectáreas, este aspecto es muy variable en muchos lotes de cultivo, al igual que las variedades establecidas, solo algunas hectáreas sembradas en los tres últimos años cumplen con esta densidad de siembra. Su producción es comercializada en el mercado de cacao "corriente". Sin embargo, se producen almendras de cacao con una gran diversidad de características sensoriales propias y diferenciales que los potencializan como cacao finos y de aroma.

Referente a la mano de obra utilizada en las unidades productivas cacaoteras, se encontró que la familia es la base de sostenimiento y quehaceres necesarios para el cultivo, el hombre trabaja en la siembra, poda, limpia y deshierbe, abonamiento, riego, control de insectos, plagas y enfermedades; las mujeres y jóvenes apoyan en las actividades de recolección, rotura o descacotado de mazorcas, eliminación de hilo o placenta y puesta a punto de cacao en baba. Se contrata mano de obra externa muy pocas veces, especialmente durante la cosecha. El valor jornal se encuentra entre 5 a 8 dólares americanos (20.000 a 30.000 pesos colombianos); en algunas unidades productivas se incluye el almuerzo y la jornada de trabajo se realiza aproximadamente entre las cinco de la mañana a las dos de la tarde.

La mano de obra que se emplea en las fincas para el manejo del cultivo de cacao es de tipo familiar, siendo las actividades de recolección, apertura y desgrane las de mayor participación d emano de obra femenina. En muchos casos y durante buena parte del año, la unidad productiva necesita personal temporal adicional para las labores de manejo del cultivo tales como la poda, deshierbe, cosecha y desgrane; no obstante, se evidenció en todas las regiones del país, la dificultad para conseguir mano de obra, ya que ésta abandona las prácticas agrícolas con el fin de desarrollar otro tipo de actividades como las relacionadas con el transporte y la construcción.

Igualmente, se observó que el nivel de aplicación de abonos o fertilizantes es muy bajo, son muy pocos los productores que tienen implementado un plan de 
fertilización adecuado más por su baja capacidad de compra que por conocimiento, son conscientes que la planta necesita de nutrientes para su productividad y desarrollo pero por sus bajos ingresos no tienen como invertir en estos insumos, desde el 2016 se vienen desarrollando proyectos a favor de los pequeños productores gestionado por la Secretaría de agricultura Departamental y algunas alcaldías como la de Manaure y La Jagua de Ibirico para mejorar la productividad y calidad de la almendra tales como Programa de transformación productiva y Alianzas productivas.

Lo anterior produce cosechas con un número de granos por mazorca muy variables entre 35 a 50 dependiendo a la variedad, al igual que el tamaño de las almendras; la cosecha se da en dos temporadas, de abril a junio la primera y la otra entre octubre y diciembre. Acorde a lo observado, la fermentación es realizada en cajones de madera, canecas plásticas, baldes, sacos o bolsas; su inicio se da el mismo día en que es cosechada la mazorca y dura entre 4 a 6 días. Muy pocos productores controlan temperaturas de fermentación, ninguno controla grados Brix y $\mathrm{pH}$. Algunos productores no fermentan los granos de cacao, cosechan, descacotan y colocan a secar directamente, este tipo de productores en su gran mayoría venden a intermediarios. Fedecacao y la Compañía nacional de chocolates por medio de sus equipos técnicos realizan en sus intervenciones capacitaciones que buscan concientizar, mejorar e implantar la fermentación en pequeños productores con el fin de mejorar la calidad sensorial de las almendras.

Luego de la fermentación los pequeños productores realizan el secado aprovechando la luz solar y las temperaturas del día entre las nueve de la mañana a 3 de la tarde durante tres o cuatro días aproximadamente cuando la lluvia se los permite. Como equipos de secado utilizan marquesinas, casas elbas, bandejas de maderas, plásticos, superficies de concreto u otra área que le permita exponer los granos al sol para su secado. Lo ideal para el secado son las marquesinas y las casa elba, pero son muy poco los productores que las poseen debido al costo de fabricación, lo cual repercute en la calidad sensorial del grano por posibles sabores y aromas absorbidos en la superficie de secado. Al igual que en los fertilizantes, los proyectos incluyen la entrega de cajones fermentadores, casa elba o marquesinas con el fin de mejorar la calidad y que el productor reciba una mejor paga. 
Para determinar el punto óptimo de secado los productores toman un puñado de almendras y las aprietan para ver si crujen a la fuerza realizada, también por la experiencia, ciertos aromas típicos le permiten determinar que están listos para vender. Algunos productores lo hacen por amistad 0 reconocimiento de intermediarios, otros directamente con la Compañía nacional de chocolates y muy pocos lo venden a la asociación. La norma ICONTEC 1252 define los parámetros para compra y venta como cacao premio, cacao corriente y pasilla. Los intermediarios realizan la compra por diferencia de precio comprando en campo para luego clasificar, almacenar y esperar para vender a la compañía nacional de chocolates o compradores localizados en otros departamentos.

Desde lo anterior, para cafés especiales y cacao en el Departamento del Cesar existen alrededor de 50 Asociaciones de Productores localizadas en los diferentes municipios con un área promedio de 2 hectáreas, actualmente el cacao y el café son cultivos priorizados en el Plan de Desarrollo Departamental 2016 2019 "El Camino del Desarrollo y la Paz". A través de la secretaria de agricultura departamental y el programa "Cesar Siembra" ha incentivado el cultivo del cacao por medio del establecimiento de un vivero específicamente para clones de cacao en convenio con la Compañía Nacional de Chocolates y AGROSAVIA estratégicamente ubicado en el municipio de Codazzi para el apoyo de los proyectos a ejecutar como los de alianzas productivas, Programa de Transformación Productiva y Compensación Ambiental, entre otros (CAMPO, 2018).

Identificado con los ODS, los cultivos de Café y Cacao por múltiples razones se puede decir son verdaderamente amigables con el medio ambiente. De hecho, se desarrollan de manera ideal dentro de los sistemas agroforestales, asociados con cultivos de ciclo corto, sombríos temporal y sombrío permanentes. Lo anterior es acorde a lo propuesto por Gianezini y Elias (2021), al afirmar que Ios ODS, EN LA AGENDA 2030 "sirven de guía para consolidar el cambio del planeta. Los ODS se ponen en práctica como responsabilidad de los gobiernos, órganos privados, comunitarios y de la sociedad civil", al igual que las empresas asociativas rurales de café y cacao (Gianezini y Elías, 2021).

Desde el punto de vista ambiental y productivo presentan una serie aspectos positivos tales como: preservar la biodiversidad, conservar o propiciar 
un microclima favorable, aumentar la productividad vegetal y animal, diversificar la producción, integrar la producción forestal con la agropecuaria, mitigar los efectos perjudiciales del sol, el viento y la lluvia sobre los suelos, combinar lo mejor del saber tradicional con los conocimientos modernos, asegurar la sostenibilidad a través de la intensificación apropiada en el uso de la tierra, mejorar el reciclaje de nutrientes, proteger al suelo contra la erosión, influenciar positivamente el manejo de las plagas, disminuir la competencia con el cultivo, utilizar especies multi propósito y persistentes, favorecer la regeneración rápida de hojas, propiciar la alta producción de hojarasca, mejorar la Fijación de Nitrógeno, crear un ambiente favorable al crecimiento de un sistema radical fuerte, proveer alimentos, materias primas, combustibles, forrajes y favorecer la biodiversidad, entre otros (MADR, 2013).

En ese sentido, Martínez (1987), realiza una investigación donde confirma que estos tipos de cultivos son "amigos de la sombra". Algunos de sus efectos fisiológicos son térmicos y luminosos lo cual se refleja igualmente en la sensación térmica del micro ambiente en un cultivo de Café o Cacao en Sistema Agroforestal. Igualmente estos cultivos bajo la protección de la sombra demanda menos cantidad de nutrimentos debido a las cantidades bajas de los productos de fotosíntesis, ya que no requieren de tanto nitrógeno y fósforo para formar proteínas, ni tanto potasio para estimular el crecimiento y acelerar la translocación de carbohidratos hacia el sistema radicular.

De la misma manera, Martínez (1987) cita a diferentes investigaciones donde afirman que los árboles de sombra asociados al cultivo del cacao proporcionan condiciones ambientales más estables produciendo abundantes floraciones acompañadas de grandes fructificaciones que solo tienen lugar durante los períodos uniformes de humedad. En Bahía. Brasil, se determinó que la humedad anual promedio del aire en cacaotales colocados a plena exposición era del 85 por ciento, mientras la de los colocados a la sombra era del 90,4 dentro del cultivo. Así mismo, Los árboles de sombra permiten un mejor uso de los fertilizantes aplicados al cacao, pues el fertilizante que se perdería por lixiviación es aprovechado por los árboles de sombrío lo cual evita posibles fenómenos de eutrofización por fertilizantes que el cultivo deje de consumir.

Apoyando lo anterior, el Ministerio de Agricultura y Desarrollo Rural de 
Colombia junto con FEDECACAO, afirman que los modelos agroforestales producen una serie de beneficios ambientales como la conservación del agua (cantidad y calidad) por medio de una mayor infiltración y reducción de su escurrimiento superficial, minimizando la contaminación y sedimentación de los cursos de agua, y mejorando la protección de las riberas. La reducción de la erosión: Las copas de los árboles, la hojarasca, las ramas, partes de los frutos, flores y otros residuos, cubren el suelo y reducen el impacto de la lluvia sobre el suelo. Los residuos de las copas que caen al suelo junto a las raíces, mejoran la estructura de este y su fertilidad, aumentando su contenido de nitrógeno y favoreciendo la retención de nutrientes como se mencionó anteriormente.

\section{CONCLUSIONES}

Como se puede ver, el café especial y el cacao se presentan para los pequeños productores rurales como motores de desarrollo de su economía agrícola. Su producción y comercialización generan múltiples agronegocios y oportunidades que adicionan valor a sus cadenas productivas de forma sostenible, estos tienen mercados de gran aporte en utilidades. Así mismo, vinculan un número significativo de pequeños productores que han visto en estos dos cultivos una posibilidad de mantenerse dentro del aprovechamiento de sus unidades productivas rurales con el fin de dar sostenibilidad a sus familias y sus empresas asociativas.

Para determinar si un café es especial más allá del marketing con el que hoy se etiquetan casi todos los cafés, se requiere del reconocimiento del cliente por el trabajo realizado para producir un café que llene las expectativas o experiencias que el comprador busca y por el cual está dispuesto a pagar un mayor valor al café convencional.

Si bien el cacao no tiene una estructura asociativa fuerte como el café, se presenta como una oportunidad para aprovechar un agronegocio en crecimiento y con un mercado abierto que requiere estrategias para mejorar los eslabones que la componen.

Las cadenas de valor de cafés especiales y cacao donde participan las empresas asociativas en el departamento del Cesar están bien definidas, pero exigen de inversión en tecnología y transferencia de conocimiento para que sean 
más eficientes en cuanto al rendimiento y utilidades a favor del pequeño productor.

Estos cultivos en asocio con especies maderables en sistema agroforestal asumen una importante función en la retención de carbono en los suelos y en la madera. Esto es un beneficio económico potencial adicional para los agricultores hacia la búsqueda de mercados del carbono el cual cobra gran importancia actualmente en el mundo. Por otra parte, la conservación de la diversidad al incorporar árboles dentro de los paisajes agrícolas coadyuva en la conservación de las riberas de los ríos, permite la conexión de hábitats para animales, aves, peces y plantas. Además, embellece el paisaje y mejora las condiciones de vida para los habitantes del campo.

Los diversos factores mencionados y la ubicación estratégica de muchas pequeñas unidades productivas de cacao y café en sistemas agroforestales, organizados en empresas asociativas rurales, en zonas con alta presión sobre los ecosistemas por actividades como la deforestación, la minería y los cultivos de uso ilícito, en gran parte hacen que sean un sistema productivo apto para la preservación de muchos hábitats de importantes especies de flora y fauna, hacia la búsqueda del repensar ambiental de muchas regiones y su sostenimiento productivo en pro de la competitividad sostenible. Es decir, este tipo de empresas asociativas rurales de cafés especiales y cacao se alinean a lo propuesto en los ODS. 


\section{REFERÊNCIAS}

Agricultura y ganadería. (2019). Producción de cacao aumentó 24\% durante enero en colombia

Tomado

de: http://www.agriculturayganaderia.com/website/produccion-de-cacao-aumento-24durante-enero-en-colombia/

Bavaresco, a. (2009) proceso metodológico en la investigación. Ediluz. Maracaibo. Venezuela.

Barrera m. Arturo y sanhueza r. Ramiro. (2007).asociatividad económica en los encadenamientos productivos. Consultoría realizada por los autores para la facultad de ciencias veterinarias y pecuarias de la universidad de chile. Tomado de http://repiica.iica.int/docs/b2066e/b2066e.pdf

Campo, c. C. (2018). Programa cesar siembra. Valledupar: secretaría de agricultura y desarrollo empresarial del departamento del cesar. Gobernación del cesar.

Congreso de la república de colombia, ley 10 de 1991. Por la cual se regulan las empresas asociativas de trabajo.

Chiriboga, manuel, y juan arellano. 2007. Diagnóstico de la comercialización agropecuaria en ecuador. Implicaciones para la pequeña economía campesina y propuesta para una agenda nacional de comercialización agropecuaria". Ecuador:

Cesa/ inter cooperación/ veco. Tomado de: http://www.asocam.org/sites/default/files/publicaciones/files/dfbdfe02ffee6677d09 5db018955af9c.pdf

Fao. 2015. Pequeñas economías: reflexiones sobre la agricultura familiar, por manuel chiriboga vega. Quito, ecuador. Tomado de: http://www.fao.org/3/ai4955s.pdf

Federación nacional de cafeteros. (2019). Producción de café de colombia cae 6\% en mayo. Tomado de: http://www.cafedecolombia.com/cci-fnces/index.php/comments/produccion_de_cafe_de_colombia_cae_6_en_mayo/

Gianezini, m., \& elias, z. Dos s. (2021). Contribuições locais para consecução dos objetivos da agenda de 2030:experiências de uma universidade comunitária: local contributions towards achieving the 2030 agenda goals: experiences from a community college. Studies in social sciences review, 2(2), 109-114. Https://doi.org/10.54018/sssrv2n2-005

González bell josé. (2019). Producción de cacao evidencia un crecimiento promedio de $6,48 \%$ en los últimos 10 años. Agronegocios. Tomado de: https://www.agronegocios.co/agricultura/produccion-de-cacao-evidencia-uncrecimiento-promedio-de-648-en-los-ultimos-10-anos-2813684

Granados pérez william; muñoz vanegas carlos alberto. (2018). Cadena de cacao, 
indicadores

e

instrumentos.

Tomado

de:

https://sioc.minagricultura.gov.co/documentoscontexto/s2591-

oe5a1\%20cacao\%20sept-2018.pptx

Hernández sampieri, r., fernández collado, c., \& baptista lucio, p. (2010). Metodología de la investigación. México: mc graw hill.

Hurtado de barrera, j. (2010). Metodología de la investigación. Bogotá - caracas: sypal - ciea. Quirón ediciones.

Martínez alfonso; enríquez gustavo. (1981). La sombra del cacao. Centro agronómico tropical de investigación y enseñanza - catie. Turrialba, costa rica.

Ministerio de agricultura y desarrollo rural- madr. De colombia. (1995). Decreto 938 de 1995 . Por el cual se modifica parcialmente el decreto 2716 de 1994.

Ministerio de agricultura y desarrollo rural - madr. (2013). Guía ambiental para el cultivo del cacao. Federación nacional de cacaoteros - fondo nacional del cacao. Segunda edición.

Ministerio de agricultura y desarrollo rural- madr. De colombia. (2018).

Resolución número 0376 "por la cual se establecen los términos y las condiciones del programa incentivo gubernamental para la equidad cafetera (igec)". Tomado de:

https://www.minagricultura.gov.co/normatividad/resoluciones/resoluci\%c3\%b3n\% 20no\%20000376\%20de\%202018.pdf

Ministerio de agricultura y desarrollo rural- madr. De colombia. (2019). Café. Tomado del sistema de información de gestión y desempeño de organizaciones de cadenas- sioc: https://sioc.minagricultura.gov.co/cafe/pages/default.aspx

Usaid - agencia de estados unidos para el desarrollo internacional; la corporación pba; programa de tierras y desarrollo rural - ptdr. (2017). Estrategia de mercadeo y especialización de la producción de caña panelera en el municipio de agustín codazzi, café en el municipio de pueblo bello y mango keitt en los municipios de agustín codazzi, becerril, chimichagua y la jagua de ibirico. Informe subcontrato de precio fijo suscrito entre ard inc. Sucursal colombia y corporación para el desarrollo participativo y sostenible de los pequeños productores rurales corporación pba.

Vieytes, r. (2004). Metodología de la investigación en organizaciones, mercado y sociedad: epistemología y técnicas. Buenos aires, argentina: editorial de las ciencias. 